\title{
“POBREZA DE MUNDO". UNA INDAGACIÓN SOBRE EL HUMANISMO Y EL MUNDO DE LA VIDA EN EL PENSAMIENTO DE MARTIN HEIDEGGER
}

\author{
Hernán J. Candiloro \\ (CONICET / Universidad de Buenos Aires) \\ hernancandiloro@hotmail.com
}

\begin{abstract}
Resumen / Abstract
En 1929, Heidegger caracteriza a la animalidad del animal como "pobreza de mundo". Sin embargo, algunos años más tarde utiliza la misma expresión "pobreza" para referirse al ser del hombre y a la posibilidad de "llevar a cabo" su relación al ser a través del pensar. En este contexto, nuestro artículo se propone indagar en el significado de la "pobreza de mundo" para explicitarla como un intento de deconstrucción del humanismo tradicional, por el cual el hombre se rencuentra con su animalidad en el marco del mundo de la vida.

Palabras Clave: Heidegger, abierto, humanismo, pobreza, animalidad, mundo de la vida, horizonte, metafísica.

“POVERTY OF WORLD". AN INQUIRY INTO THE HUMANISM AND THE WORLD OF LIFE IN THE FRAME OF MARTIN HEIDEGGER'S THINKING

In 1929 Heidegger characterizes animality in terms of "poverty of world". However, some years later he uses the same expression "poverty" to mean the being of the man and the possibility of "realizing" his relation to being in general through the thinking. In this context, our article proposes an inquiry in the meaning of "poverty of world", to explicit it like an attempt to deconstruct the traditional humanism, by which the man meets again his animality in the context of the world of life.
\end{abstract}

KEY WORDS: Heidegger, open, humanism, poverty, animality, world of life, horizon, methaphysics.

\section{Introducción}

RA Una posible hipótesis para abordar coherentemente la totalidad de la obra de Heidegger consiste en tomarla como un gran diálogo (Gespräch) con aquello que el propio autor denomina historia de la metafísica. Pero un diálogo que, lejos de ser el mero intercambio de opiniones, se erige como discusión y lucha (pólemos) por el sentido de lo que se da y por aquello que la metafísica misma tiene para decirnos. El diálogo con la historia de la metafísica es así un diálogo crítico, una discusión, y también un diálogo deconstructivo por medio del cual se intentan explicitar y acrecentar las tensiones que atraviesan la metafísica. El objetivo de dicha discusión no es otro 
que poner de relieve la pregunta fundamental en la que aquella extiende sus raíces y a la que sin embargo niega, manteniéndola oculta e impensada. A esta comprensión polémica de la filosofía, entendida como el diálogo crítico con la historia de la metafísica, Heidegger la llama Destruktion.

Pero aunque la discusión de fondo sea con la historia de la metafísica como un todo que comienza con Platón y Aristóteles y concluye con Nietzsche, la Destruktion heideggeriana se medirá especialmente con ciertas configuraciones prominentes que brindan el marco y la tonalidad, el horizonte general de comprensión de toda pregunta que se inserte en la tradición. La interpretación metafísica del ser funciona como suelo para una serie de interpretaciones más particulares que a través del influjo de la ciencia moderna llegan a condicionar incluso el modo cotidiano de enfrentarse al mundo.

Uno de los aspectos destacados de esta pregnancia de la metafísica en todas las regiones de lo que se da es el humanismo, esto es, la interpretación del ser del hombre que, amparándose en la metafísica, hace de aquél una esencia "ante los ojos" determinable con claridad y distinción. Postulándolo como una sustancia cerrada sobre sí, que no necesita de ningún otro ente para ser, el hombre es separado con nitidez de la vida en general.

En tanto que sustancia cerrada sobre sí, el hombre se vuelve unidad autónoma $\mathrm{y}$ totalidad. En efecto, tal y como lo entiende el humanismo, el hombre es -desde un punto de vista estrictamente ontológico- esencialmente lo mismo que cualquier otro ente: una sustancia cerrada sobre sí a la que se le agrega una particularidad distintiva -llámese lenguaje, razón, espíritu, etc.- que lo jerarquiza y lo pone en una posición de predominio sobre el resto de lo ente. Esto nos da la pauta del carácter paradójico del humanismo que, con la intención de definir con claridad y distinción lo propio del hombre, hace de él un ente ontológicamente idéntico a cualquier otro.

El humanismo consistiría así en una tendencia que recorre la historia de la metafísica en busca de incrementar cada vez más la determinación de lo humano. A decir de Heidegger, su comienzo estaría dado por la definición aristotélica del hombre como "animal racional" que repercutiría a través de la postulación del sujeto cartesiano en la modernidad hasta llegar a su paroxismo con el "superhombre" de Nietzsche. Este último sería el grado de mayor determinación de lo propiamente humano, el acabamiento de todo lo que la definición aristotélica del hombre daba a ser pensado y, por consiguiente, el punto que señalaría el fin del humanismo y de la metafísica sobre la que aquél se sostiene (Heidegger 2000a, T1, pp. 383 y ss.). Sin embargo, es necesario prestar atención al hecho de que esta exacerbación y acabamiento de la comprensión esencialista del ser del hombre tendría como correlato la imposición del ente humano sobre el resto de lo ente a través de su dominio técnico-científico.

Esta interpretación metafísica del ser del hombre tiene dos consecuencias destacadas. Por una parte, comprendiendo al hombre como una sustancia cerrada sobre sí, lo pone a disposición para su dominio, es decir, hace de él un recurso a ser explotado como cualquier otro. Por otra parte, conlleva un doble enfrentamiento posicional y combativo- entre el hombre y el resto de los entes. El hombre pasa a estar, posicionalmente, "frente a" (gegenüber) los demás entes que hacen frente dentro del 
mundo -ya sean estos entes a la mano, ante los ojos o también otros Dasein- y este enfrentamiento posicional trae consigo otro enfrentamiento combativo en el cual el hombre se opone (gegen) a los otros entes y los estimula con el fin de extraer de ellos su energía y dominarlos (Cf. Heidegger 2005).

Tenemos entonces una ilación entre metafísica, humanismo y cierto modo de habitar el mundo por parte del hombre que nos hace patente una peculiar comprensión de la ética y la política. Ciertamente, la metafísica implica un modo en el que el hombre "es en el mundo" y determina así la estancia -el ĥ̉0 - de aquél. Entendida como negación del ámbito originario en el que se extiende la pregunta fundamental, la metafísica determina el ser del hombre como siendo una sustancia ante los ojos y de esa manera conduce al humanismo. A su vez la comprensión humanista del ser del hombre, con su consiguiente distinción y enfrentamiento de una esencia propiamente humana frente al resto de los entes, implica la puesta a disposición de la naturaleza como recurso a ser explotado indiscriminadamente por un sujeto que ha sido previamente separado de ella, pero también la puesta a disposición de ese mismo sujeto, que ha sido equiparado a una sustancia cualquiera y que puede también ser utilizado y explotado como un recurso entre otros.

En un sentido general, podemos decir que ambas perspectivas de utilización y explotación de la vida, ya sea de la así llamada vida calificada -humana- o de la vida desnuda -el mero viviente-, han sido reunidas desde la segunda mitad del siglo XX hasta la actualidad en lo que a partir de Foucault se ha dado en llamar "biopolítica", a saber: la gestión de lo viviente con vistas a su fortalecimiento y puesta a disposición para su utilización (Cf. Foucault 2007, Agamben 1998 y Esposito 2006) ${ }^{1}$.

En este contexto, el presente trabajo intentará demostrar de qué manera es posible desmontar el encadenamiento entre metafísica, humanismo y explotación técnico-científica de la naturaleza, a partir del análisis de la tesis heideggeriana acerca de la "pobreza de mundo". Para ello nos concentraremos en los análisis heideggerianos sobre la animalidad, el animal y su mundo; con la intención de esbozar lo propio del hombre, no ya en una separación respecto de su entorno sino, por el contrario, como una inserción en lo que, siguiendo la expresión acuñada por Husserl, denominaremos "mundo de la vida". Sintéticamente, intentaremos graficar lo peculiarmente humano como el modo peculiar en el que el hombre habita el mundo común a lo viviente y sobre cuya negación emerge la metafísica.

Sobre la posibilidad de pensar el debate biopolítico contemporáneo a partir de la obra de Heidegger, cf. Campbell, Timothy (2011), Improper life: technology and biopolitics from Heidegger to Agamben. Minnesota: University of Minnesota Press. 


\section{El límite de lo humano}

El humanismo persigue la determinación y radicalización de lo propiamente humano para impedir que el hombre se deshumanice ${ }^{2}$. Sin embargo, si la estructura de la definición mediante género común y diferencia específica que desde Aristóteles en adelante rige la determinación humanista del ser del hombre tiene la intención de caracterizar positivamente lo "propiamente humano", su contracara negativa yace en el hecho de que al mismo tiempo lo diferencia con nitidez del resto de lo viviente.

Ya desde la definición aristotélica el hombre se encuentra anclado en lo viviente a través de su animalidad. No obstante, su aspecto más propio reside justamente en aquello que lo separa de la vida en general, haciendo de él un viviente con cierta calificación. Si de acuerdo a esta definición el hombre es la conjunción, no sin conflicto, entre animalidad y racionalidad, lo propiamente humano reside, sin embargo, solo en esta última. Distinguiendo al hombre, la racionalidad es el signo distintivo de lo que aquél no tiene en tanto que viviente, sino como humano. La racionalidad excede así los límites de lo vital y marca un espacio en el cual el hombre trasciende lo meramente viviente. Lo propiamente humano reside pues en el hecho de trascender negando la vida, y arroja al hombre a una tensión entre lo viviente y su excedencia, entre lo vivo y lo no-vivo. El hombre es, por ende, el viviente que mantiene una relación de inadecuación con la vida que por una parte es, pero que por la otra niega.

Sostenido en la necesidad de resolver esta inadecuación y con el objeto de lograr una definición clara y distinta, es decir, amparado en el presupuesto de la onticidad del ser del hombre, la tendencia humanista fortalece el componente que es postulado como siendo específicamente humano, en detrimento de su componente animal-viviente. Por consiguiente, el humanismo lleva a cabo, al mismo tiempo, la radicalización de lo propiamente humano y su imposición sobre lo viviente en general, esto es, la puesta a disposición de lo común-viviente a manos de lo peculiarmente humano. Esta radicalización de lo propiamente humano se hace especialmente manifiesta con la aparición de la racionalidad moderna entendida como cálculo que busca controlar y dominar lo que se da a través de la técnica y la ciencia (Cf. Heidegger 2005).

Así pues, en términos generales, el humanismo realiza un corrimiento desde el género común hacia la diferencia específica y persigue una caracterización de la esencia humana en su puridad, rechazando cualquier contaminación y marca de la alteridad. De esta manera, el gesto humanista se corresponde con un movimiento correlativo de expulsión de la alteridad, necesario para la concreción del cierre sobre sí. Dicho más específicamente, la determinación de lo humano en el hombre requiere la expulsión de los elementos vitales y comunes que lo "rebajan" a la condición de mero viviente, es decir, específicamente, de su animalidad.

2 "[...] eso es el humanismo: meditar y cuidarse de que el hombre sea humano en lugar de no-humano, "inhumano", esto es, ajeno a su esencia" (Heidegger 2000b, p. 264). 
Pero es necesario insistir en la diferencia que la interpretación tradicional presupone entre el hombre y lo humano. Si el primero es el objeto privilegiado del humanismo, esto es, el espacio donde este último introduce escisiones y suturas con vistas a la determinación de una esencia clara y distinta, lo humano, en cambio, es lo propio del hombre, aquello que separa a este último con claridad y distinción del resto de lo viviente. De esta manera, el humanismo distingue lo propio en el hombre para separar a éste del resto de lo viviente. Sin embargo, si, por un lado, la determinación de lo humano se sostiene sobre un movimiento de negación de la vida que no puede ser interrumpido sin que se pierda el contorno que permite su identificación, por otro, esta negación de lo viviente no puede sino ser ambigua: mediante la separación de la vida ésta es al mismo tiempo reincorporada en la esencia del hombre como su aspecto negativo, esto es, como aquello que debe ser negado para que el hombre sea tal. Por lo tanto, la vida no es sin más expulsada del hombre, sino que es mantenida en una suerte de estado intermedio "de excepción" entre una exclusión inclusiva y una inclusión exclusiva a través del cual es incorporado negativamente (Agamben 1998, pp. 25-84).

La vida desnuda pertenece también, aunque negativamente -es decir, como elemento forcluido- a la esencia del hombre; y es necesario que permanezca así para que lo propiamente humano no pierda sus contornos. A diferencia de la zoé-vida desprovista de toda cualificación- la bíos lleva en sí misma la marca de la negatividad de la cual no puede desprenderse sin autoinmunizarse y destruirse a sí misma (Cf. Esposito 2005). Por consiguiente, si lo viviente representa el afuera de lo humano, aquello que es excluido de lo humano para que éste pueda ser determinado, este afuera no puede sino ser la condición de posibilidad de lo humano mismo.

\section{Lo humano como apertura}

Si el humanismo encuentra lo propiamente humano en una esencia clara y distinta -en un qué- Heidegger, por el contrario, lo hará en su modo de inserción en el mundo de la vida -en un cómo-. Pero aún en el mismo mundo -cuyo horizonte común este trabajo intenta explicitar-, los modos de inserción de lo "no más que viviente" y del "hombre" difieren entre sí. Como veremos más adelante, lo que distingue al hombre del animal no es entonces una esencia no-animal o no-viviente ni nada "ante los ojos" sino, en cambio, la manera en la que este animal llamado hombre sale fuera de sí hacia el mundo de la vida. Lo peculiar del hombre será, podemos adelantarlo, la ex-sistencia.

El anti-humanismo de Heidegger choca, pues, con el humanismo tradicional. Mientras que éste define lo humano negativamente, aquél opone una caracterización positiva del hombre a través de la cual se hace explícito su vínculo con el mundo de la vida. La deconstrucción del humanismo implica así una serie de sustracciones: en primer lugar, sustraer al hombre de su captura bajo la forma de una esencia metafísica determinada con claridad y distinción y, en consecuencia, definible lingüística y 
categorialmente; segundo, y no de menor importancia, sustraer a la vida del "estado de excepción" en el que ha sido colocada, el cual implica su puesta a disposición para ser explotada; y en tercer lugar, sustraer al hombre y a la vida de la dinámica de enfrentamiento en la que lo ha posado la modernidad. Lo humano deja entonces de ser entendido como límite y separación y pasa a ser un modo particular de vínculo del hombre con el mundo y, consecuentemente, con el resto de los entes.

Ese horizonte que hace posible la donación del ente constituirá el tema fundamental de toda la obra heideggeriana, y ya sea que se lo comprenda en relación con la posibilidad de la muerte como sucede en Ser y tiempo o en referencia al pensar y al acontecimiento (Ereignis) como en la obra posterior, mantiene un vínculo específico con lo que Heidegger denomina "mundo".

Entendido como condición última de posibilidad de toda dación, el mundo de la vida remite a lo que en Ser y tiempo Heidegger denomina "mundanidad del mundo". Pero además, y puesto que es "de la vida", señala la apertura del ser en tanto que horizonte compartido con el resto de lo viviente, y no en sus determinaciones peculiarmente humanas. El mundo de la vida es entonces la apertura de la vida y para la vida, es decir, el horizonte que hace posible todo acontecer y transcurrir en el tiempo. En este sentido, este horizonte originario no puede prescindir de una dimensión temporal fundamental, aunque ésta exceda la mera historicidad peculiar al Dasein. Todo darse es darse en el horizonte del tiempo, y sin embargo, como afirma el propio Heidegger, no solo el hombre, sino también el resto de los vivientes tienen una relación con el tiempo (Zeitigkeit), aunque ella no presente los caracteres de la comprensión histórica ni el sentido del tiempo (Zeitsinn) (Heidegger 1998, p. 133). Dicho sencillamente, el horizonte originario excede pues los límites metafísicos de lo humano y arroja al hombre en un "mundo común de la vida".

\section{4. ¿Qué significa animal?}

La definición aristotélica del hombre como "animal racional" rige la interpretación humanista del ser del hombre. Sin embargo, pese a estar determinada por la comprensión metafísica de lo que se da, en lo esencial esta definición no es falsa:

El hombre se entiende como animal rationale. Esta determinación no es sólo la

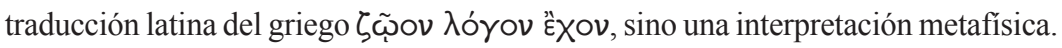
En efecto, esta determinación esencial del ser humano no es falsa, pero sí está condicionada por la metafísica. Pero es su origen esencial y no sólo sus límites lo que se ha considerado digno de ser puesto en cuestión en Ser y tiempo" (Heidegger 2000b, p. 266).

La deconstrucción procederá entonces operando sobre los vestigios de este origen esencial rápidamente capturado por la primacía del ente, con la intención de recuperar 
el sentido de la definición, obturado por las capas encubridoras de la metafísica ${ }^{3}$. En este sentido, si bien la definición tradicional del hombre -y es importante repetirlo-en lo esencial no es falsa, será cuestión, no obstante, de preguntarnos cuál es su sentido, qué tiene todavía para decirnos a más de dos milenios de su primera formulación.

Tal y como nos ha sido legada, la definición tradicional del hombre presupone la comprensión del ser como ente. Es necesario entonces deconstruir lo que hay de metafísico en la definición aristotélica, para de esa manera hacer explícito lo que aún perdura del pensar original que se encuentra en su base. ¿Qué significa, pues, animal racional por fuera de su determinación metafísica?

En el curso de 1929, Heidegger se pregunta explícitamente por la animalidad $y$, en el marco de la pregunta fundamental por la esencia de la vida, hace de ella la pregunta rectora de la investigación. La pregunta rectora de Ser y tiempo -publicado apenas dos años antes de que tuviera lugar el curso- se refería, en cambio, al ser del Dasein, con vistas a la explicitación del ser en su sentido general. No hay allí referencias a la animalidad, sea ya en relación con el Dasein -por ejemplo bajo la forma de la corporalidad-o bien a lo viviente en general. ¿Cómo se explica esta ausencia en una obra que se ocupa de manera rectora por el ser del hombre? ¿Y cómo se explica cuando, en el fragmento citado de Carta sobre el humanismo, el propio Heidegger afirmará que era ese mismo origen esencial de la definición tradicional el que Ser y tiempo se proponía elucidar para poner en cuestión?

La cita de la Carta sobre el humanismo nos da la pauta de que el preguntar de Ser y tiempo era anterior a la caracterización del hombre como animal racional e intentaba explicitar el ámbito del que dicha definición surgía. Por consiguiente, si en Ser y tiempo faltaba una pregunta por la animalidad del Dasein era porque su objetivo consistía en explicitar un horizonte anterior, vinculado a la comprensión del mundo y a partir del cual era factible encontrar su sentido.

Sin embargo, se hace evidente un cambio en la dirección del preguntar: la pregunta fundamental ya no tiene como objetivo la explicitación del ser en su sentido general sino ahora la de la esencia de la vida. Y la pregunta rectora se ocupa de la animalidad, en consideraciones que, aunque estén mayormente referidas al viviente animal distinto al Dasein, no hacen sino revertirse sobre este último enriqueciendo la caracterización de su propia experiencia del mundo ${ }^{4}$. De todos modos, debemos reparar

3 "Un fenómeno puede además estar enterrado. Esto implica: estaba ya descubierto, pero volvió a quedar encubierto. Este encubrimiento puede llegar a ser total, o bien, y es la regla, lo ya descubierto es aún visible, pero sólo en la forma del "parecer ser..."” (Heidegger 2009: p. 46).

4 "Ciertamente, en un sentido positivo hemos aprendido bastante poco sobre la esencia del mundo, sino sólo sobre el animal y su no tener mundo, su perturbamiento (Bennomenheit). Con ello conocemos meramente el lado negativo del asunto. $\mathrm{Y}$, sin embargo, tenemos que pensar que nosotros mismos somos el lado positivo, que nosotros mismos existimos en el tener mundo" (Heidegger 2007, p. 327). 
en que la vida ya había sido objeto de investigaciones anteriores a Ser y tiempo, aunque en esta obra haya sido desestimada para el proyecto de una restitución de la pregunta por el ser y la ontología.

Podemos observar una torsión en el camino del pensar heideggeriano. Éste comenzaría preguntando por la esencia de la vida, para luego devenir en la pregunta por el ser y más tarde retornar a la pregunta inicial. ¿Cuál es el sentido de esta torsión? La respuesta a esta cuestión, aunque al pasar, está dada en Ser y tiempo: "la vida es una forma de ser a la que le es inherente un "ser en el mundo"" (Heidegger 2009, p. 269). Así pues, las investigaciones anteriores acerca de la esencia de la vida carecían de una correcta explanación del mundo, de la que Ser y tiempo viene a hacer su tema principal. Recordemos, pues, que su hilo conductor es el existenciario del "ser en el mundo" y avanza profundizando en sus distintos estratos, para llegar a su nivel de mayor profundidad en la temporalidad.

En este sentido, podemos decir que la explicitación del ser del Dasein y en particular del "ser en el mundo" constituye el marco dentro del cual adquiere sentido todo preguntar, sea ya respecto del ser, de la vida, del hombre o del animal. Sin la explicitación de dicho marco, las consideraciones acerca de la vida presentadas con anterioridad a Ser y tiempo resultaban abstractas y esencialmente incompletas, puesto que: "La vida es una forma de ser peculiar, pero por esencia accesible sólo en el "ser ahí"” (Heidegger 2009, p. 62) o, dicho de otra manera, porque la ontología del Dasein "es anterior a una ontología de la vida" [el énfasis es de Heidegger] (Ibíd, p. 270). Esto nos indica dos puntos que debemos tener presente: primero, que la relación esencial entre vida y Dasein presupone el mundo; y segundo, que el retorno heideggeriano al concepto de vida trae implicada una resignificación de este último en el marco de la analítica existenciaria desarrollada en Ser y tiempo.

De acuerdo a su relación con el mundo, Heidegger distingue tres regiones de la vida: lo sin-mundo (weltlos), lo pobre de mundo (weltarm) y lo configurador de mundo (weltbildend) (Heidegger 2007, §42); para luego tomar a lo pobre de mundo -que coincidirá con la animalidad-como guía para la investigación acerca de la esencia de la vida. En este sentido, si el correcto acceso a la pregunta por el ser en su sentido general debía estar mediado por la explanación del ser del Dasein -y eso en razón de su preeminencia óntico-ontológica (Heidegger 2009, §4)- nos encontramos ahora con que la correcta explanación de la esencia de la vida debe estar conducida por el desarrollo de la animalidad del animal. Sin embargo, y resulta fundamental tener esto presente, tanto en un caso como en el otro el término que actúa como mediador es el mismo: el mundo. Si el hilo conductor de Ser y tiempo era el "ser en el mundo", en el curso sobre los conceptos fundamentales será la "pobreza de mundo", entendida como aquella instancia que, por encontrarse en un lugar intermedio entre lo "configurador de mundo" y lo "sin mundo", posee un mayor "valor comparativo" y por lo tanto constituye un acceso privilegiado para la explicitación del horizonte que reúne a las tres regiones 
de la vida ${ }^{5}$. Dicho sencillamente, si el curso toma como guía a la región de lo "pobre de mundo" es porque se propone la elucidación de esa instancia fundamental y originaria del mundo a la que hemos dado en llamar "mundo de la vida".

Por consiguiente, podemos afirmar que tanto en Ser y tiempo como en Los conceptos fundamentales el objetivo general es el mismo, a saber: elucidar el horizonte último común a la vida. Ya sea a través de la explicitación del "ser en el mundo" como un existenciario del Dasein o de la "pobreza de mundo" del animal, lo que se busca en ambos textos es el despliegue del estrato más básico a partir del cual puede sostenerse que hay una dación.

\section{5. "Pobreza de mundo" (Weltarm)}

Esta caracterización de la animalidad como pobreza de mundo ha dado lugar a múltiples interpretaciones que tienden a considerar que Heidegger sigue inserto en una perspectiva humanista. Menospreciando al animal, Heidegger pondría en el centro al Dasein humano y reproduciría la misma comprensión de lo viviente que era objeto de su crítica ( cf. por ejemplo, Derrida 2008).

Gran parte de la relevancia de esta crítica se debe a que su estructura se corresponde punto por punto con el análisis que estos mismos autores llevan a cabo del nazismo, entendido como la sobrepotenciación del sujeto humano ${ }^{6}$. De acuerdo a esta crítica, el anti-humanismo de Heidegger estaría al servicio de un humanismo exacerbado -nazismo- por no haber sido lo suficientemente radical ${ }^{7}$.

Frente a estas interpretaciones es importante detenerse en qué significa "pobreza de mundo" para Heidegger, en especial teniendo en cuenta que en 1945, pocos días antes del final de la Segunda Guerra Mundial, sostendrá un discurso que lleva por título, justamente, "La pobreza"; y cuya importancia para repensar retrospectivamente la problemática de la animalidad tiende a ser soslayada. Aunque en dicho discurso no se

5 "Si por mundo entendemos lo ente en su accesibilidad respectiva, si la accesibilidad de lo ente es un carácter fundamental del concepto de mundo, entonces el animal, si es que lo vivo es capaz de acceder a algo distinto, está del lado del hombre. En el animal y en el hombre hallamos un tener mundo. Por otra parte, si la tesis intermedia acerca de la pobreza de mundo del animal ha de mantenerse legítimamente y si la pobreza es un carecer y el carecer es un no tener, entonces el animal está del lado de la piedra [...] Aquí se entrelazan en cierta manera los extremos de falta de mundo y de configuración de mundo" (Heidegger 2007, p. 250).

6 Nos referimos especialmente a gran parte de la recepción francesa de Heidegger: E. Levinas, J. Derrida, J.-L. Nancy, y P. Lacoue-Labarthe, entre otros.

7 En este punto es necesario mencionar que también existe otra crítica muy distinta a la señalada, que apunta a identificar de manera directa al anti-humanismo de Heidegger con su compromiso con el nacional socialismo (Cf. Ferry y Renaut 1988 y 2001). 
haga mención del animal, es necesario prestar atención al hecho de que allí la pobreza es caracterizada exactamente del mismo modo que en el seminario de 1929, a saber: como pobreza que es en realidad una riqueza ${ }^{8}$, como "carecer" y "tener [mundo] al modo del no tener"9. Pero también es necesario prestar atención al hecho de que en la Carta sobre el humanismo, -publicada en 1946-Heidegger apela otra vez a la pobreza para referirse a lo propio del hombre, entendido ahora como aquello que lo arroja en la apertura del ser y donde el hombre debe "descender" para reencontrar su humanidad, paradójicamente obturada por el humanismo. Allí Heidegger afirma que a través del pensar el hombre "gana la esencial pobreza del pastor" (Heidegger 2000b, p. 281) ${ }^{10}$.

No solo la repetición de una misma palabra-Armut-, sino también la misma caracterización de la pobreza, ya sea que se refiera al animal en el curso de 1929, o al hombre, en el discurso de 1945 y en la Carta sobre el humanismo, nos llevan a concluir que Heidegger se refiere a un mismo fenómeno. Pero como dijimos, en el último período no se menciona al animal, sino que la pobreza remite allí al hombre que se encuentra ante un momento decisivo - como puede ser la circunstancia de enunciación del propio discurso a pocos días del final de la guerra-, y la apertura del mundo en tanto tal. La pobreza es allí la ocasión para que el hombre logre una relación "más viva" (lebendiger) con aquello que lo rodea (Heidegger 2006, p. 101).

La pobreza de mundo a través de la cual es caracterizada la animalidad del animal debe, pues, ser repensada en el contexto de estas otras referencias que aparecen entre 1945 y 1946 y que refieren al ser del hombre. Ello implica que también deben ser repensados la animalidad, el hombre y la relación que los vincula en el seno de la vida. Lejos de ser una peculiaridad denigratoria del animal, la pobreza parece ser, en cambio, el lugar de confluencia entre el hombre y el viviente animal. Siguiendo esta

8 "Entre nosotros, todo se concentra sobre lo espiritual, nos hemos vuelto pobres para llegar a ser ricos" (Heidegger 2006, p. 93); "[...] pobreza de mundo del animal, pobreza que, dicho a grandes rasgos, es, no obstante, una riqueza" (Heidegger 2007, p. 309). "Aparentemente más pobres, pero más ricos en lo que se nos otorga casualmente (Zu-fall)" (Heidegger, 1994a, p. 71).

9 "Lo pobre no es en modo alguno el mero "menos", el mero "más escaso" frente al "más" y el "mayor". Ser pobre no significa simplemente no poseer nada o poseer poco o poseer menos que el otro, sino que ser pobre significa carecer" (Heidegger 2007, p. 245); "Ser pobre en el sentido de encontrarse pobre, Armmütigkeit, no es una mera indiferencia frente a la posesión, sino precisamente aquel excepcional tener como si no tuviéramos" (Ibíd., p. 246); "El animal tiene algo y no tiene algo, es decir, carece de algo. Lo expresamos así: el animal es pobre de mundo, carece fundamentalmente de mundo" (Ibíd., p. 262) [el énfasis es siempre del autor]. "¿Qué quiere decir "pobre”? ¿En qué consiste la esencia de la pobreza? ¿Qué quiere decir "rico", si sólo llegamos a ser ricos en la pobreza y por ella? "Pobre" y "rico", en el sentido habitual, conciernen a la posesión, al tener. La pobreza es un no-tener y, a decir verdad, un carecer de lo necesario. La riqueza es un no-carecer de lo necesario, un tener más allá de lo necesario" (Heidegger 2006, p. 107).

10 [la cursiva es mía. HJC] Otras menciones a la pobreza pueden encontrarse en las páginas 288 y 297 del mismo texto. 
línea, pobreza sería otro nombre para la humanidad del hombre, solo que ahora entendida a la manera de una apertura, y no ya como una diferencia y separación respecto de lo viviente. Una apertura que no es propiedad del hombre, sino a la que, por el contrario, el hombre mismo debe apropiarse para realizar su posibilidad más propia.

"Con toda seguridad: eso de lo que carecemos no nos pertenece como propio, de tal modo, es verdad, que nos importa que pueda pertenecernos como propio. Eso de lo que carecemos, nosotros no lo tenemos, sino que lo carecido nos tiene a nosotros" [el énfasis es de Heidegger] (Heidegger 2006, p. 113) ${ }^{11}$.

El hombre solo puede dejarse templar por la pobreza, para de esa manera dejar ser la humanidad que lleva en sí. Dejándose atravesar por la aperturidad de la apertura el hombre lleva a cabo o consuma (vollbringt) su ex-sistencia. Consumación de la exsistencia a la que Heidegger llama "pensar" y que arroja al hombre a un nuevo habitar poético caracterizado por su atención al mundo (Cf. Heidegger 1994b).

\section{La pobreza como lo señalado}

La pobreza es pues “carecer”. Pero el carecer no es una simple ausencia. Carecer es el no tener algo que debería estar, o mejor, el tener una privación. Más explícitamente, Heidegger aclara que la pobreza es de mundo, es decir, un tener mundo al modo del no tenerlo. Lo que se tiene no es un mundo efectivo, históricamente articulado, sino que esta privación de mundo refiere, en cambio, a la posibilidad de tener un mundo histórico. Así pues, la pobreza de mundo no remite a ningún mundo particular, sino a la potencia de mundo, el horizonte último a partir del cual los entes vienen a la presencia. La pobreza de mundo es un tener mundo al modo de la potencia, y por lo tanto el carecer no es sino una potencia imposibilitada de actualizarse (Cf. Agamben 2007). Una potencia que permanece como resto en toda actualización y que en su resistir abre al mundo en su mundanidad. La actualización a la que dicha potencia resiste no es otra que la caída, la cercanía óntica que el Dasein tiene con su mundo circundante aunque cotidianamente ella implique una lejanía ontológica producto de la pérdida de sentido de su habitar y el olvido del mundo.

Podemos extraer algunas conclusiones preliminares de esta caracterización de la "pobreza". En primer lugar, puede percibirse la cercanía de lo mentado por la expresión "pobreza de mundo" y la "mundanidad del mundo". En efecto, y como veremos más adelante, también la mundanidad del mundo aparece en Ser y tiempo al modo de un "carecer" de mundo en el cual, cayendo los entes en la insignificatividad, aparece el mundo con toda su riqueza ontológica.

11 He retocado la traducción, HJC. 
En segundo lugar, podemos ver que al ser definida como "pobreza de mundo", la animalidad del animal se encuentra sustraída a la caída. Este punto es de máxima importancia, ya que llevará a que Heidegger sostenga que el animal no tiene acceso al ente en tanto tal. Nuevamente, lejos de ser una caracterización tendiente al menosprecio de la posición ontológica del animal, dicha afirmación se explica porque éste se encuentra más allá de lo ente, arrojado en el puro venir a la presencia, en la pura potencia de mundo o en la pura apertura sin experiencia alguna de la diferencia ontológica. Sin embargo, es importante notar que, en esta sustracción a la caída, la animalidad no es sino el lugar de una posible resistencia frente al imperar metafísico del ente.

En tercer lugar, podemos vislumbrar cierta familiaridad entre la pobreza y el existenciario de la "angustia" tal y como éste aparece en Ser y tiempo. Ello por dos razones primordiales. Primero, porque en el curso de 1929, Heidegger aclara que "ser pobre es un encontrarse pobre" (Heidegger 2007, p. 246) -en una clara referencia al existenciario del "encontrarse" (Befindlichkeit)-, es decir, que la pobreza es, como la angustia, un temple de ánimo. En este sentido, recordemos que el mundo solo puede ser abierto de un modo primario si el Dasein está templado anímicamente y, por lo que hemos sostenido hasta aquí, la pobreza no es otra cosa que esta apertura primigenia del mundo. Segundo, porque, a diferencia del resto de los temples de ánimo, la pobreza y la angustia tienen la peculiaridad de hacer patente al mundo en su mundanidad, es decir, el mundo en lo que tiene de apertura con independencia de aquello que muestra. Tanto en la angustia como en la pobreza se da el carecer los entes.

Ciertamente, la angustia que templa originalmente el ser del Dasein hace caer al ente en la más plena insignificatividad, a tal punto que ningún ente -ni siquiera los otros Dasein- pueden venir a la presencia en tanto tales. En efecto, Heidegger afirma que en la angustia el Dasein es sustraído a la caída, en una afirmación que, claro está, no deja de ser problemática si tenemos presente que también la caída es un carácter esencial del Dasein, un existenciario ${ }^{12}$. Sin embargo, y he aquí el punto fundamental que debemos retener, todo ello no implica en lo más mínimo que el mundo en tanto tal desaparezca. Más bien todo lo contrario: solo en el marco de esta insignificatividad del ente que arrastra consigo al "mundo" -icon comillas!-, puede aparecer en todo su esplendor el mundo -ahora sin comillas-, entendido como el horizonte último ${ }^{13}$. Un

12 "Pero en la angustia hay la posibilidad de un señalado abrir, porque la angustia singulariza. Esta singularización saca al Dasein de su caída y le hace patentes la propiedad y la impropiedad como posibilidades de su ser" (Heidegger 2009, p. 211).

13 Al respecto, es importante recordar la aclaración hecha por el propio Heidegger: "Nosotros reservamos terminológicamente la expresión mundo para la significación fijada en el número 3. Las veces en que se use en el sentido mencionado en primer término, se marcará esta significación por medio de comillas". Esto quiere decir que "mundo" "se emplea como concepto óntico y entonces significa la totalidad de los entes que pueden ser "ante los ojos" dentro del mundo" y mundo "en un sentido óntico, mas ahora no como los entes que el Dasein, por esencia, no es, y que pueden hacer frente dentro del mundo, sino como aquello "en que" un Dasein fáctico, en cuanto es este Dasein "vive"”, (Heidegger 2009, pp. 77-78). 
horizonte que, en lugar de presentar un fundamento inconmovible, abre el abismo de la pregunta fundamental, en razón de que carece de todo ente y de toda presencia. En este sentido, y para ser estrictos, debemos decir que más que un temple de ánimo, la pobreza es precisamente aquello que la angustia tiene de señalado respecto de los otros temples anímicos. Lo señalado de la angustia -y que la hace anterior a otros temples de ánimo- reside justamente en que carece de referencias a un ente en particular, y por ello mismo puede abrir el ámbito anterior a partir del cual los entes aparecen significativamente para el Dasein.

Recién en este punto podemos comprender cabalmente qué significaba ese horizonte abisal sobre el que se sostenía la metafísica y que nos arrojaba a la profundidad de la pregunta fundamental: el abismo de ésta no es sino el carecer que se abre en la pobreza, y se patentiza como el "faltar los entes". Faltar que debe ser distinguido de la simple ausencia, puesto que señala en dirección a los entes que faltan. En dicho señalar se abre la posibilidad de un habitar distinto por parte del hombre, que llega así a estar "en una relación más viva (in einer lebendigeren Beziehung) con aquello que lo rodea" (Heidegger 2006, p. 101) ${ }^{14}$. Esta expresión -más viva- no debe ser tomada como mera casualidad: abriendo el horizonte originario, al que hemos caracterizado como mundo de la vida, el hombre puede desplegar lo que tiene de viviente, en lugar de intentar separarlo alienándose. Así pues, si la filosofía -entendida como la reflexión peculiar a la historia de la metafísica- se esforzaba por capturar, determinar y dominar lo que se da, el pensar, en cambio, se propone reunir a la vida en ese horizonte último que le es peculiar y en relación con el cual puede desplegar positivamente sus posibilidades propias.

Pero si lo señalado de la angustia reside en estar atravesada por la pobreza, otro tanto debe decirse del pensar que emerge producto de la deconstrucción de la metafísica en el final de la filosofía. En efecto, también el pensar es caracterizado por Heidegger como "pobre de pensamiento" (gedanken-arm) y al mismo tiempo como un campo fértil que abre el ámbito originario (Gegend) cuando el hombre se deja templar por la "serenidad" (Gelassenheit):

Sin embargo, cuando somos faltos de pensamiento no renunciamos a nuestra capacidad de pensar. La usamos incluso necesariamente, aunque de manera extraña, de modo que en la falta de pensamiento dejamos yerma nuestra capacidad de pensar. Con todo, sólo puede ser yermo aquello que en sí es base para el crecimiento, como, por ejemplo, un campo. Una autopista, en la que no crece nada, tampoco puede ser nunca un campo yermo. Del mismo modo que solamente podemos llegar a ser sordos porque somos oyentes y del mismo modo que únicamente llegamos a ser viejos porque éramos jóvenes, por eso mismo también únicamente podemos llegar a ser pobres e incluso faltos de pensamiento porque el hombre, en el fondo de su esencia, posee la capacidad de pensar (Heidegger 1994, p. 17). 
La pobreza presenta, pues, una fuerte relación con la angustia, el pensar y la serenidad. En todos los casos, lo destacado consiste en el carecer los entes a través del cual es (re) abierta la apertura originaria. La pobreza se encuentra entonces muy lejos de indicar una valoración negativa hacia la animalidad, sino que, muy por el contrario, constituye aquello que el hombre debe recuperar y reafirmar como instancia de resistencia frente al imperar de la metafísica y la dominación tecnocientífica de lo viviente.

\section{Volver a los entes mismos}

El "mundo" - con comillas- solo puede aparecer sobre el trasfondo del mundo -sin comillas. El ente aparece a partir de un trasfondo abisal capaz de ser pensado en la profundidad del carecer peculiar a la pregunta fundamental. El proyecto de Heidegger consiste en la explicitación positiva de este horizonte originario, condición de posibilidad de todo aparecer. Pero en una explicitación positiva que, muy lejos de ser una mera aventura teórica, "lleva a cabo" o "consuma" la relación del hombre con el ser y con ella su humanidad. Ahora bien, ¿cómo puede aparecer la condición de posibilidad de todo aparecer? ¿Cuál es el modo de ser de la condición de posibilidad de todo lo que es?

El pensar heideggeriano se debate en la tensión abierta por la recursividad de ambas preguntas. El faltar el "mundo" de la pobreza hace aparecer la mundanidad del mundo con toda su fuerza. En este punto, Heidegger distingue el mero faltar entendido en términos de "indigencia" (Not) de una auténtica "necesidad" (Notwendigkeit) espiritual que atraviesa al hombre en su carecer (Heidegger 2006, pp. 109 y ss.).

No en el mero trato indiferente con los entes, pero tampoco en una huida o aislamiento respecto del "mundo" de la cotidianidad, sino volviendo a los entes mismos a partir de la apertura por la cual éstos vienen a la presencia, el hombre reencuentra la cercanía con lo ente y consigo mismo. Este "volver a los entes" en un sentido renovado puede ser entendido como la versión heideggeriana del famoso lema que regía la fenomenología de Husserl: “¡a las cosas mismas!”.

La reapertura implica el retorno a los entes a partir de ese mundo que ha sido abierto. Pero un retorno que, al igual como sucedía con Husserl, se encuentra mediado por un cambio radical en la actitud hacia lo que se da y que en el caso de Heidegger es posible porque el hombre es, al igual que el animal, pobre. Superar la metafísica no significa entonces dejarla atrás como algo que deba ser sobrepasado, sino que el pensar, en tanto encarna dicha superación de la metafísica, consiste más bien en un hundirse en los entes y en la metafísica misma hacia la pobreza originaria del hombre:

El pensar no supera la metafísica por el hecho de alzarse por encima de ella sobrepasándola y guardándola en algún lugar [clara alusión a la Aufhebung hegeliana. HJC], sino por el hecho de volver a descender a la proximidad de lo más próximo. El descenso, sobre todo cuando el hombre se ha estrellado ascendiendo hacia la subjetividad, es más difícil y peligroso que el ascenso. El descenso conduce a la 
pobreza de la ex-sistencia del homo humanus. En la ex-sistencia se abandona el ámbito del homo animalis de la metafísica" (Heidegger 2000b, p. 288) ${ }^{15}$.

El pensar es el descenso a la pobreza de la ex-sistencia del hombre. Y ese pensar sustrae al hombre de la comprensión metafísica de la animalidad como siendo un mero "ente ante los ojos". Lo humano no reside ya en una diferencia específica sostenida negativamente en relación con la animalidad sino, en cambio, en el vínculo por el cual el hombre se inserta en lo abierto. En este sentido, el pensar es la consumación de la inserción originaria del hombre en la apertura, por la cual el hombre se mantiene en una exterioridad originaria que lo expone ante la alteridad. Así pues, si el movimiento propio del humanismo consistía en separar y aislar lo distintivo del hombre, la deconstrucción heideggeriana explicitará lo peculiarmente humano como el estar saliendo de sí hacia el mundo, que es llevado a cabo plenamente en el pensar.

Ahora que hemos repensado la animalidad del animal por fuera de su determinación metafísica, sustrayéndola a su captura bajo la forma de una esencia clara y distinta, es menester que repensemos también la humanidad del hombre a partir de ella, puesto que no debemos olvidar que el hombre es, él también, un ser viviente y un animal.

Sin embargo, aunque animal, el hombre es un animal caído, en constante trato con los entes. Solo el ente separa al hombre del animal, ente que es sobrepotenciado por la metafísica en un gesto que es al mismo tiempo la radicalización de la separación en que consiste el humanismo. Su deconstrucción tiene como consecuencia la explicitación del horizonte común del cual la separación emerge y en el cual puede volver a hundirse. Este horizonte no es otro que el mundo de la vida y que, en cuanto es la condición última de posibilidad de todo aparecer, aparece como el temporalizarse de lo que se da.

El hombre es el animal que se encuentra constantemente junto a los entes, el animal caído. Solo el ente separa al hombre del animal, y aquel es sobrepotenciado por la metafísica, que radicaliza así la separación en que consiste el humanismo. La liberación del horizonte originario implica así la liberación de la animalidad del hombre, esto es, la reafirmación de aquella pobreza animal que lo atraviesa y que éste tiende a negar. Sin embargo, esta liberación persiste siempre como tarea a ser realizada, y que hace coincidir la recuperación de la pobreza originaria con la recuperación del "fundamento metafísico" de su animalidad, oculto bajo las distintas caracterizaciones científicas que establecen paralelos sin elucidar el horizonte sobre el que estos se dan:

La animalidad del hombre tiene un fundamento metafísico más profundo que el que pueda enseñarse nunca de modo biológico-científico con la referencia a una especie animal existente que se asemeja aparentemente en ciertos aspectos de una manera exterior (Heidegger 2000a, p. 455).

15 El interpolado es mío. HJC. Hay una alusión en la misma dirección de este fragmento en la página 297. 
El hombre es pobre en razón de que está vivo y, en particular, de que es animal. De esta manera, el desprecio que la historia de la metafísica ha ejercido sobre la animalidad se corresponde con la obturación de la pobreza que conduce al olvido del ser. Por lo tanto, la animalidad es, por un lado, un espacio de resistencia frente al humanismo, la metafísica y el dominio tecnocientífico de la naturaleza, y por otro, aquello que, incluyendo al hombre en el mundo de la vida, lo deja participar de la apertura del ser. El hombre es humano porque, ante todo, es animal.

Solo elucidando el mundo de la vida puede el hombre ser propiamente humano, aunque en un sentido renovado y deconstructor del humanismo tradicional. La radicalización de la diferencia específica llevada a cabo por el humanismo equivale a lo contrario de la tarea propiamente humana y representa más bien su tergiversación. El auténtico humanismo -auténtico a un punto tal que, como dice Heidegger, habría que dejar de llamarlo así- ${ }^{16}$, ya deconstruido de sus determinaciones metafísicas, debe desmontar las diferencias radicales para elucidar el peculiar modo de inserción en lo común.

\section{Conclusión}

A lo largo del presente trabajo hemos procurado presentar el proyecto heideggeriano de una Destruktion de la metafísica desde la perspectiva de una crítica al humanismo y a la comprensión tecnocientífica de la naturaleza. Para ello hemos intentado establecer un paralelo entre la reapertura del horizonte originario -al que hemos relacionado con la pregunta fundamental de la metafísica-y la elucidación de un mundo común a lo viviente al que, siguiendo la expresión de Husserl, hemos denominado "mundo de la vida". En los términos en los que lo hemos presentado, éste sería el estrato más básico del mundo, el trasfondo último de toda dación, al que hemos equiparado con la "mundanidad del mundo", con la apertura y la Gegend. Ello indica que, pese a las torsiones y variaciones del preguntar heideggeriano, consideramos que la obra de Heidegger puede ser leída en el marco de un mismo proyecto tendiente a la explicitación de este trasfondo último al que en nuestro trabajo hemos abordado en relación con lo viviente.

Asimismo, hemos presentado la relación entre metafísica, humanismo y comprensión tecnocientífica de la naturaleza, haciendo patente el interés de Heidegger por deconstruir la interpretación de lo que se da como esencias "ante los ojos", claras y distintas y pasibles de ser dominadas y explotadas. Por otra parte, hemos mencionado la relación de presuposición entre dicha interpretación de lo que se da, y la discusión actual acerca de la biopolítica, lo que nos ha permitido posicionar la obra de Heidegger como una referencia ineludible al respecto. En este sentido, hemos sostenido que la deconstrucción que Heidegger opera a nivel ontológico tiene fuertes consecuencias

"Pero, suponiendo que un título tenga alguna importancia, ¿se puede seguir llamando humanismo a ese pensamiento? Está claro que no, puesto que el humanismo piensa metafísicamente" (Heidegger 2000b, p. 275). 
antropológicas y políticas. De esta manera, consideramos que la crítica heideggeriana a la metafísica prepara la sustracción del existente humano y del resto de lo viviente a los dispositivos de captura de la metafísica y así pone en cuestión la dominación y explotación de la vida.

Frente a una comprensión del hombre que lo separa y opone al resto de lo viviente, Heidegger procuraría elucidar un horizonte común y anterior - presupuesto- a dicha separación que, coincidiendo con el horizonte último de toda dación, le permitiría al hombre volver a los entes en un sentido renovado. La apertura del horizonte originario del que los entes provienen tiene como consecuencia que el hombre reencuentre su lugar propio en relación con el ser y, junto con ello, reencuentre también la posibilidad de un habitar distinto en el seno del mundo de la vida, sustrayéndose al enfrentamiento con la naturaleza.

Elucidando el horizonte común a la vida, el hombre puede, a decir de Heidegger, reencontrar una relación "más viva" con aquello que lo rodea. Nosotros hemos comprendido dicha relación no solo como un poner al ente bajo una luz renovada, sino también como la apertura de una comunidad posible con lo viviente en general y con el animal que él mismo es. Dicha relación solo es posible si el hombre se deja templar por la pobreza, impidiendo el cierre sobre sí y permitiendo que el ente destelle en el horizonte del mundo de la vida. Manteniendo abierto el mundo de la vida entendido como el horizonte originario del aparecer, tiene lugar el pensar del que proviene la apertura del ser. Un pensar que se hace manifiesto en la palabra y el habitar poético que, llevando al hombre de un modo renovado hacia los entes que lo rodean, le permite desplegar sus posibilidades más peculiares.

Finalmente, concluimos que la apertura del hombre, entendida como pobreza de mundo, reside en su animalidad. Sin embargo, entre el hombre y el animal persiste aún una inadecuación: el hombre es el animal caído y por eso debe remontar el ente en dirección hacia el mundo de la vida. Solo el ente separa al hombre del animal y, por esa razón, en tanto primacía del ente, la metafísica no es sino la radicalización de la distinción entre ambos.

La reapertura del mundo de la vida implica un retorno "más vivo" a los entes mismos. Un retorno que abre la posibilidad de un nuevo habitar en el hombre, que ya no lo opone a la vida sino que ahora, en cambio, lo caracteriza positivamente a partir de su animalidad.

\section{Referencias bibliográficas}

Obras de Heidegger

(1994a) Serenidad. Trad. Y. Zimmermann. Barcelona: Serbal.

(1994b) "Construir, habitar, pensar", Conferencias y artículos. Trad. E. Barjau. Barcelona: Serbal; pp. 107-119. 
(1998) GA 38 - Logik, als die Frage nach dem Wesen der Sprache. Frankfurt am Main: Klostermann.

(2000a) Nietzsche. Trad. J. L. Vermal. Barcelona: Destino.

(2000b) "Carta sobre el humanismo", Hitos. Trad. H. Cortés y A. Leyte. Madrid: Alianza; pp. 259-297.

(2005) "La época de la imagen del mundo", Caminos de bosque. Trad. H. Cortés y A. Leyte. Madrid: Alianza; pp. 63-90.

(2006) La pobreza. Trad. I. Agoff. Buenos Aires: Amorrortu.

(2007) Los conceptos fundamentales de la metafísica. Mundo, finitud y soledad. Trad. A. Ciria. Madrid: Alianza.

(2009) El ser y el tiempo. Trad. J. Gaos. Buenos Aires: FCE.

Bibliografía secundaria

Agamben, Giorgio (1998), Homo sacer. El poder soberano y la nuda vida. Trad. A. Gimeno Cuspinera. Valencia: Pre-textos.

(2007), "La potencia del pensamiento", La potencia del pensamiento. Trad. E. Castro y F. Costa. Buenos Aires: Adriana Hidalgo; pp. 351-368.

Derrida, Jacques (1989), Del espíritu. Trad. M. Arranz. España: Pre-textos. (2008), El animal que luego estoy si(gui)endo. Trad. C. de Peretti y C. R. Marciel. España: Trotta.

Ferry, Luc y Renaut, Alain (1988), La penseé 68. Paris: Gallimard. (2001), Heidegger y los modernos. Trad. A. Bixio. Buenos Aires: Paidós.

Foucault, Michel (2007), El nacimiento de la biopolítica. Trad. H. Pons. Buenos Aires: FCE.

Esposito, Roberto (2005), Immunitas: protección y negación de la vida. Trad. L. Padilla López. Buenos Aires: Amorrortu. (2006), Bios: biopolítica y filosofía. Trad. C. R. Molinari Marotto. Buenos Aires: Amorrortu. 